\title{
Naked DNA immunization with full-length attachment gene of human respiratory syncytial virus induces safe and protective immune response
}

\author{
M. E. HAMAD ${ }^{1}$, H. M. AMER ${ }^{1,2}$, M. A. FARRAG ${ }^{1}$ A. H. OSMAN ${ }^{3}$, F. N. ALMAJHDI ${ }^{*}$
}

\begin{abstract}
${ }^{1}$ Department of Botany and Microbiology, College of Science, King Saud University, 11451 Riyadh, Saudi Arabia; ${ }^{2}$ Department of Virology, ${ }^{3}$ Department of Pathology, Faculty of Veterinary Medicine, Cairo University, 11221 Giza, Egypt
\end{abstract}

Received January 30, 2017; revised September 13, 2017; accepted March 28, 2018

\begin{abstract}
Summary. - Development of potent vaccine for human respiratory syncytial virus (HRSV) that confers better protection than natural infection remains a global challenge. Vaccination with naked DNA is considered successful approach for the control of many viral diseases. In this study, the potential of DNA vaccination using full-length attachment gene of HRSV type A Saudi strain cloned in pcDNA3.1+vector (pcDNA/GA) was evaluated in BALB/c mice. The expression efficiency of pcDNA/GA was first confirmed in HEp-2 cells on RNA and protein levels. Mice immunization with either $\mathrm{pcDNA} / \mathrm{GA}$ or the positive control formalin-inactivated vaccine (FI-RSV) has generated significant serum antibody concentration in ELISA $(7.31 \pm 0.418$ and $9.76 \pm 0.006 \mu \mathrm{g} / \mathrm{ml}$, respectively) with superior neutralizing activity. Similarly, both immunogens evoked robust HRSV-specific CD8+ T-cell response in ELISPOT assay compared to mice immunized with pcDNA3. $1^{+}$vector or saline (negative controls). Challenge of the immunized mice with the wild-type HRSV did not provoke clinical symptoms or mortality in any mice group. On the $7^{\text {th }}$ day post-challenge, mice were euthanized and lungs were extirpated for evaluation of viral load, histopathological changes and cytokine profile. A significant diminish in the viral load and histology score were concluded in lungs of pcDNA/GA immunized mice compared to those immunized with FI-RSV and negative controls. The pulmonary cytokine profile of pcDNA/GA immunized mice displayed notable upregulation of Th1-associated cytokines while that of FI-RSV immunized mice exhibited high levels of Th2-associated cytokines. In conclusion, the DNA vaccine candidate pcDNA/GA has proven prominent efficacy and safety in mouse model, which encourages further evaluation in clinical trials.
\end{abstract}

Keywords: attachment glycoprotein; challenge; DNA vaccination; human respiratory syncytial virus; mice immunization; T-helper biased response

\section{Introduction}

Human respiratory syncytial virus (HRSV) is a common cause of acute lower respiratory tract infection (ALRTI) manifested by bronchiolitis, pneumonia and chronic obstructive pulmonary disease (COPD) in infants and young children (Polack, 2015). It has been estimated that 64 million children are suffering from HRSV-associated ARTIs

*Corresponding author. E-mail: majhdi@ksu.edu.sa; phone: +966$11-4677778$

Abbreviations: $\mathrm{FI}=$ formalin-inactivated; $\mathrm{HRSV}=$ human respiratory syncytial virus; IFN- $\gamma=$ interferon gamma; $\mathrm{NU}=$ neutralization unit; $\mathrm{SFC}=$ spot forming count annually worldwide (Tregoning and Schwarze, 2010). More severe lower respiratory tract infection that requires hospitalization is developed in approximately 3.4 million children with an estimated mortality of 66,000-199,000 each year (Nair et al., 2010). HRSV natural infection does not induce long-lasting immunity, which causes children to undergo multiple infections throughout their lives. HRSV has been identified by WHO as a global disease and is currently on the 'watching list' of WHO's initiative vaccine research group (WHO, 2005).

Vaccination is considered the most effective and economic measure for prevention of a multitude of infectious diseases worldwide (WHO, 2005). To date, no effective HRSV vaccines are commercially available. The development of HRSV 
vaccine that confers better protection than natural infection remains a global challenge for the medical and scientific communities. A formalin-inactivated (FI-RSV) vaccine candidate was produced during the 1960s but it induced serious side effects and even death in some vaccinated children upon subsequent natural HRSV infection (Kim et al., 1969). Studies in animal models suggested that FI-RSV enhanced severe pulmonary disease post-challenge through evoking Th2 biased response and excessive eosinophil infiltration into the lungs (Kim et al., 2015; Waris et al., 1996). Live attenuated HRSV vaccines were generally immunogenic but they were replication inefficient and lacked the genetic stability (Karron et al., 2015; Wright et al., 2000). Subunit vaccines have proven superior safety profile in vivo; however, their immunogenicity interfered by the existence of maternal antibodies in children during the first months of life (Murphy et al., 1991; Vaughan et al., 2005).

DNA vaccines have emerged during the last two decades as a novel way of vaccination that provides targeted immunogenicity and higher safety. DNA vaccines are easy to construct and stable upon long-term storage. They permit prolonged expression of folded and glycosylated antigens, induce effective antibodies and $\mathrm{CD}^{+} 8 \mathrm{~T}$-cells, and generate significant immunological memory (Li et al., 2012; Liu et al., 2006). The ability of DNA vaccines to induce Th1 biased immune response and to overcome the inhibitory effects of maternal antibodies highlights the promise of DNA vaccine in developing effective HRSV vaccine candidates (Wu et al., 2009). Several studies are ongoing and animal/clinical studies are still under investigation (Stab et al., 2013; Wu et al., 2009; Xu et al., 2014).

The attachment $(\mathrm{G})$ glycoprotein is the major transmembrane spike of HRSV that mediates virus adsorption to host cell (Ghildyal et al., 2005). Recombinant G glycoprotein produced in Escherichia coli either alone (BBG2Na) or in combination with fusion (F) and matrix (M2) proteins (rRFM2G) was immunogenic and protected mice and cotton rats from HRSV infection (Goestch et al., 2000; Power et al., 1997; Subbarayan et al., 2010). Recombinant influenza, Sendai and Newcastle disease viruses that express chimeric HRSV G protein on their surfaces were able to elicit high levels of neutralizing antibodies and significantly decreased the lung viral load in immunized animals (Jones et al., 2012; McGinnes et al., 2011; Quan et al., 2011). Albeit immunogenic in BALB/c mice, utilization of $\mathrm{G}$ protein in the form of adjuvanted subunit or viral vectored vaccines was not recommended due to several safety considerations (Bembridge et al., 1998; Sparer et al., 1998).

In the current report, the potential of DNA vaccination using full-length HRSV G gene for disease control in infants and young children was investigated in a mouse model. The generated vaccine candidate has elicited potent antibody and cytotoxic $\mathrm{T}$ lymphocytes (CTL) responses and confirmed pulmonary Th1 biased immune response post-challenge. These preliminary data suggested the compatibility of the DNA vaccine candidate for further testing in non-human primates and in clinical trials.

\section{Materials and Methods}

Virus and cells. HRSV-A strain Riyadh 38/2008 was isolated and characterized from a clinical specimen obtained from an 8-monthold male infant hospitalized in a tertiary referral center at Riyadh (Almajhdi et al., 2014). Human epidermoid carcinoma (HEp-2) cells were maintained in Dulbecco Modified Eagle's Medium (DMEM) supplemented with 10\% fetal bovine serum (FBS), $2 \mathrm{~mol} / \mathrm{l}$ L-glutamine, $100 \mathrm{U} / \mathrm{ml}$ penicillin, $100 \mu \mathrm{g} / \mathrm{ml}$ streptomycin, and $0.25 \mu \mathrm{g} / \mathrm{ml}$ amphotericin B (Thermo Scientific, USA) at $37^{\circ} \mathrm{C}$ and $5 \% \mathrm{CO}_{2}$. The virus was propagated in HEp-2 cells for 3 successive passages and a high-titer stock of $10^{6} \mathrm{TCID}_{50} / \mathrm{ml}$ was aliquoted and stored at $-80^{\circ} \mathrm{C}$ until use.

Construction of recombinant immunization vector. Viral RNA was extracted using QIAamp viral RNA mini kit and cDNA was synthesized by Sensiscript reverse transcription kit (Qiagen, Germany) according to the manufacturer's instructions. Full-length G gene sequence (Genbank Acc. No. JX131638) was amplified using GeneAmp ${ }^{\circ}$ High-Fidelity PCR kit (Applied Biosystems, USA) and the primers: HRSV-GAF-HindIII (5'-CC CAAGCTTATGTC CAAAA CCAAGGAC-3') and HRSV-GAR-EcoRI (5'-CCG GAATTCTCATTTTGTTGTGTTGGA TG-3'). The amplified PCR product was agarose gel-purified using QIAquick gel extraction kit (Qiagen) and was cloned into the immunization vector pcDNA3.1 $1^{+}$ (Thermo Scientific) via 5' HindIII and 3' EcoRI. The recombinant plasmid clone (designated as pcDNA/GA) was verified by restriction endonuclease digestion, PCR and DNA sequencing. A high concentration of endotoxin-free plasmid stock was prepared using PureYield $^{\mathrm{ma}}$ plasmid maxiprep system (Promega, USA).

Preparation of formalin-inactivated HRSV vaccine (FI-RSV). FIRSV vaccine was prepared for use as a positive control in animal experiments as described before (Kim et al., 1969). Briefly, semiconfluent monolayers of HEp-2 cells were infected with HRSV strain Riyadh 38/2008 at MOI of 0.1. Virus adsorption was allowed for $1 \mathrm{~h}$ before fresh DMEM with 1\% FBS, L-glutamine, 100 units/ml penicillin, $100 \mu \mathrm{g} / \mathrm{ml}$ streptomycin, and $0.25 \mu \mathrm{g} / \mathrm{ml}$ amphotericin B were added. After complete development of CPE (3-4 days), cells were subjected to 3 cycles of freezing and thawing, and medium was clarified by centrifugation at $3,000 \mathrm{x}$ g for $10 \mathrm{~min}\left(4^{\circ} \mathrm{C}\right)$. Formalin was added to the clarified supernatant $(1: 4,000)$ and incubated at $37^{\circ} \mathrm{C}$ for $72 \mathrm{~h}$. Inactivated virus particles were precipitated by ultra-centrifugation at $50,000 \mathrm{xg}$ for $30 \mathrm{~min}\left(4^{\circ} \mathrm{C}\right)$. The pellet was resuspended in serum free medium (1:25 of the original volume), and aluminum hydroxide ( $4 \mathrm{mg} / \mathrm{ml}$ ) was added and incubated overnight for virus adsorption. The mixture was precipitated at $1000 \mathrm{x}$ g for $10 \mathrm{~min}\left(4^{\circ} \mathrm{C}\right)$ and the pellet was resuspended in serum free medium (1:100 of the original volume) (Waris et al., 1996). 
Transfection and expression analysis. In vitro expression of pcDNA/GA was confirmed in HEp-2 cells on both RNA and protein levels. Cells were plated in two separate 6-well plates at a density of $2 \times 10^{5} \mathrm{cells} / \mathrm{ml}$ one day before transfection. Transfection was done with $1 \mu \mathrm{g} /$ well of the plasmid preparation with the aid of FuGene 6 transfection reagent (Promega). Empty pcDNA3.1 $1^{+}$transfected and non-transfected cells were included as negative controls. Three days later, RNA was extracted from the transfected cells of one plate using RNeasy mini kit (Qiagen) and genomic DNA was eliminated using RNase-free DNase set (Qiagen) according to the manufacturer's protocol. Amplification of $\mathrm{G}$ gene sequence was performed using OneStep RT-PCR kit (Qiagen) and the primers: HRSV-GA-F (5'-TCATTTTGTTGTG TTGGATGAAGATGG-3') and HRSV GA-R (5'-TCATTTTGTTG TGTTGGATGAAGATGG-3'). Cells of the second plate were fixed $72 \mathrm{~h}$ post-transfection using chilled $80 \%$ acetone and were stained with HRSV-specific FITC conjugated goat polyclonal antibodies (Thermo Scientific). The plate was examined, and images were captured by IN Cell analyzer 2000 (GE Healthcare, UK).

DNA immunization and mice challenge. Six-to-eight weeks old female BALB/c mice were obtained and maintained in SPF conditions with standard feeding at the animal facilities of College of Pharmacy, King Saud University, Riyadh. Mice were divided into 5 groups (12 mice each) and were immunized twice (days 0 and 28). Mice groups were injected intra muscularly (i.m.) in musculus tibialis anterior with $100 \mu \mathrm{l}$ of pcDNA/GA (50 $\mu \mathrm{g}$ in saline), pcDNA3. $1^{+}\left(50 \mu \mathrm{g}\right.$ in saline), FI-RSV $\left(3 \times 10^{5} \mathrm{TCID}_{50}\right.$ equivalent in saline) or saline-alone (negative and mock-infected control groups). Fourteen days after the second immunization, mice of each group were separated into two clusters; one cluster $(n=3)$ was euthanized for serum and spleen collection, while the other cluster $(n=9)$ was anesthetized and challenged by intranasal administration of HRSV strain Riyadh 38/2008 ( $10^{5} \mathrm{TCID}_{50} /$ mouse). Mock-infected control group only received DMEM by the intra-nasal route. Post-challenge, physiological parameters, clinical signs and mortality were daily recorded. All animal experiments were approved by the Research Ethics Committee, King Saud University (code 4/67/352665).

Evaluation of antibody and $T$ cell responses. Mice sera, collected after the second immunization, were screened for HRSV specific antibodies using mouse respiratory syncytial virus IgG ELISA kit (MyBioSource, USA) according to the manufacturer's instructions. The antibody level was measured at wavelength $405 \mathrm{~nm}$ by EL $\mathrm{x}$ 800 microplate reader (BioTek, USA) and the concentration of antibodies was calculated according to the standard curve generated by six standards included in the kit. Neutralizing antibodies were determined by micro-neutralization assay as described earlier (Graham et al., 1988). The neutralization titer was expressed as the reciprocal of the highest serum dilution that blocked virus infectivity (neutralization units $(\mathrm{NU}) / \mathrm{ml}$ ).

Specific T cell response was assayed on mice splenocytes using interferon gamma (IFN- $\gamma$ ) ELISPOT kit (U-CyTech biosciences, Netherlands) according to the manufacturer's protocol (De Rose et al., 2005). Briefly, splenocytes ( $2 \times 10^{6}$ cells) of each mice group were seeded in RPMI-1640 medium supplemented with 10\% FBS and antibiotics at 48 well plates. One row was left untreated as negative control and a second received concanavalin A ( $2 \mu \mathrm{g} /$ well $)$ as positive control. Cells in the other wells were pre-stimulated by a peptide mixture of HRSV-A G-derived immunodominant CD8+ T cell epitopes ( $0.5 \mu$ g of each peptide/well; purity $>98 \%)$. The peptides include SNNPTCWAICKRIPNKKP (aa: 177-194), WAICKRIPNKKPG (aa: 183-195), ESNPSPSQVYTTSEH (aa: 183-197), EGNPSP SQVSTTSEY (aa: 271-285) (Thinkpeptide, UK) (Lukens et al., 2006; McDermott et al., 2014; Varga et al., 2000). After 24 hours of incubation at $37^{\circ} \mathrm{C}$, cells were transferred to 96 -well ELISPOT plate (coated with anti-IFN- $\gamma$ antibodies) in 3 -fold serial dilutions from $1 \times 10^{5}$ to $3 \times 10^{3} /$ well (in triplicates). Incubation with the appropriate stimulus was extended for further $16 \mathrm{~h}$ to allow spot formation using biotinylated detection antibodies and GABA solution. Spots were developed using activator solution and examined under an inverted microscope (Eclipse TS100, Nikon, Japan). Spots of negative control were subtracted from the spots in test wells.

Histopathology, virus titration and cytokine profiling of lungs after challenge. Seven days post-challenge, mice were euthanized, and lungs of each group were harvested and divided into three sets (3 mice each); one set was formalin-fixed and prepared in thin sections for staining with hematoxylin and eosin (Murawski et al., 2010). Histopathological examination of lung tissues was conducted in a blind-fashion and images were documented using Eclipse E-800 microscope equipped with DXM1200C digital camera (Nikon, Japan). Scoring of the histopathological changes followed the system developed by Hwang et al. (2014) that ranged from $0-3$ according to the degree of inflammatory cell infiltration in the peri-bronchiolar space. The second set of lungs was individually homogenized, clarified by centrifugation at 3,000 rpm for $30 \mathrm{~min}$ $\left(4^{\circ} \mathrm{C}\right)$, and filtered using $0.22 \mu \mathrm{m}$ syringe filters. The lung virus titers were determined by infectivity assay and were expressed as TCID $_{50}$ per gram of lung tissue. The third set of lungs was homogenized in liquid nitrogen and total RNA was isolated from the tissue homogenate using RNeasy mini kit (Qiagen). Pulmonary gene expression of Th1 and Th2 cytokines was evaluated using RT ${ }^{2}$-PCR Profiler arrays (Qiagen) on ABI Prism 7500 Sequence detection system (Applied Biosystems). Cycle-threshold $\left(\mathrm{C}_{\mathrm{t}}\right)$ values were obtained using a constant baseline for all PCR runs. Five endogenous expression controls provided by the array (Actb, B2m, Gapdh, Gusb, and Hsp90ab1) were used to calculate the arithmetic mean which was then set as the $\mathrm{C}_{\mathrm{t}}$ value for normalization. RT-PCR array results were analyzed and heatmaps were generated by Scatter-plots using online $\mathrm{RT}^{2}$ - PCR Profiler data PCR array analysis software (http://www.qiagen.com/ $\mathrm{sa} /$ shop/genes-and-pathways/data-analysis-center-overview-page). Experimental gene expression was defined as $\Delta \Delta \mathrm{Ct}$ and calculations were normalized to the housekeeping genes.

Statistical analysis. The data are presented as means and standard deviations. Difference of means between test and control groups was analyzed using unpaired Student's $t$-test and was considered statistically significant when $\mathrm{p}$ value is less than 0.05 . 

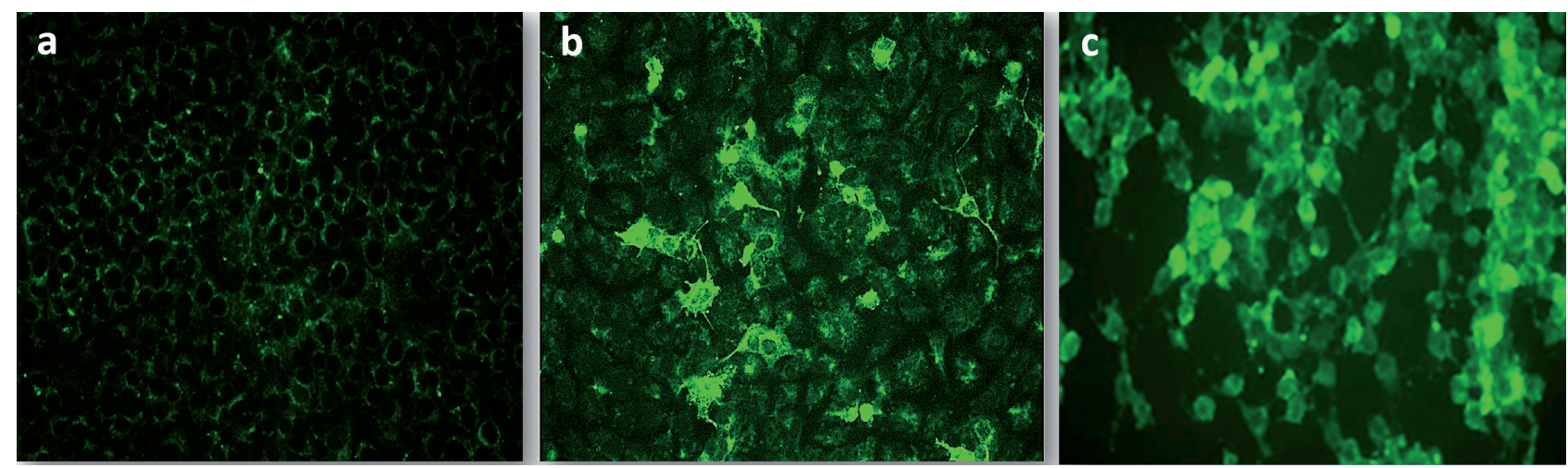

Fig. 1

Immunofluorescent assay of HRSV-A G protein expression in HEp-2 cells

(a) cells transfected with pcDNA3.1 $1^{+}$control vector, (b) cells transfected with pcDNA/GA vector showing diffuse intracellular fluorescent staining, (c) cells infected with wild-type HRSV showing extensive intracellular fluorescence with evidence of cell detachment. Magnification 200x.

\section{Results}

pcDNA/GA vector expresses HRSV G protein in HEp-2 cells

The potential of pcDNA/GA vector to express HRSV G protein was first verified in HEp- 2 cells before being utilized in immunization studies. Cells transfected with pcDNA/GA, pcDNA3. $1^{+}$or DNA-free medium were incubated for 3 days and total RNA was extracted. DNA elimination was further conducted to avoid amplification signals developed from the remnants of transfected plasmid constructs. Distinct RT-PCR amplicons with the expected size of full-length G gene (894 bp) were generated from HEp-2 cells transfected with pcDNA/GA but not from those transfected by $\mathrm{pcD}$ NA3. $1^{+}$or DNA-free medium (data not shown). On the other hand, the protein expression was assayed by direct immunofluorescence. Only cells transfected with pcDNA/ GA have shown diffuse intracellular staining similar to that developed in HRSV infected cells (Fig. 1).

\section{Immunization with pcDNA/GA elicits high level of} antibodies in mice

Induction of HRSV-specific antibody response in BALB/c mice immunized i.m twice with pcDNA/GA (4-week interval) was measured in sera samples collected 14 days after the second immunization by ELISA. Significant antibody levels were developed in mice immunized with both FI-RSV and pcDNA/GA with a mean antibody concentration of $9.76 \mu \mathrm{g} /$ $\mathrm{ml}(\mathrm{SD}=0.006, \mathrm{CV}=0.46 \%)$ and $7.31 \mu \mathrm{g} / \mathrm{ml}(\mathrm{SD}=0.418$, $\mathrm{CV}=4.28 \%)$, respectively; $\mathrm{p}$ value 0.001 . No distinct antibodies were recognized in the sera of pcDNA3.1+ immunized and negative control mice (Fig. 2). The neutralizing activity of the raised antibodies was further evaluated by micro-neutralization assay in HEp-2 cells. HRSV-specific antibodies in the sera of mice immunized with FI-RSV and pcDNA/GA were capable to inhibit the virus activity with a mean antibody titer of $3.7 \pm 1.3 \times 10^{3}$ and $4.8 \pm 1.7 \times 10^{3} \mathrm{NU} /$ $\mathrm{ml}$, respectively. Sera of control mice failed to develop signs of virus neutralization.

\section{pcDNA/GA evokes robust HRSV-specific $C D 8^{+} T$ cell} response

The immunogenicity of $\mathrm{pcDNA} / \mathrm{GA}$ vector was further confirmed by measuring IFN- $\gamma$ secretion of splenocytes ex vivo using ELISPOT assay. The assay results were calculated by subtracting the mean number of background

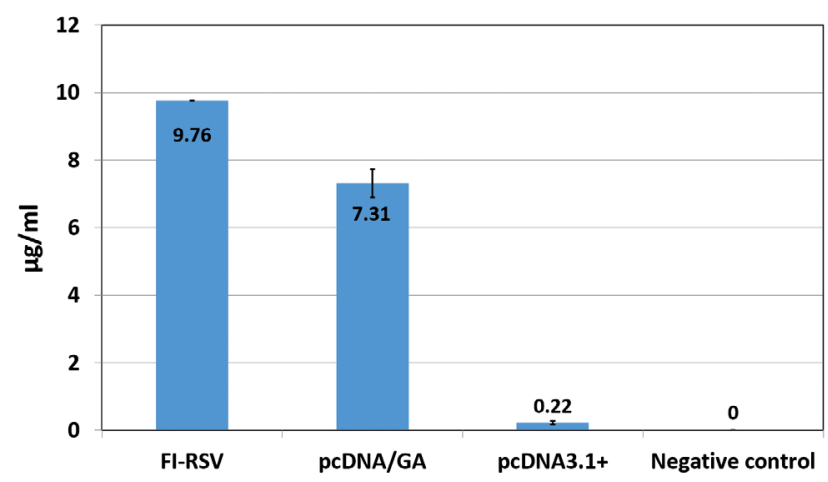

$p$ value $=0.001$

Fig. 2

Concentration of HRSV-specific antibodies in sera of immunized mice groups

The bars show the mean antibody concentration $(\mu \mathrm{g} / \mathrm{ml})$. Standard deviations are shown as error bars. 

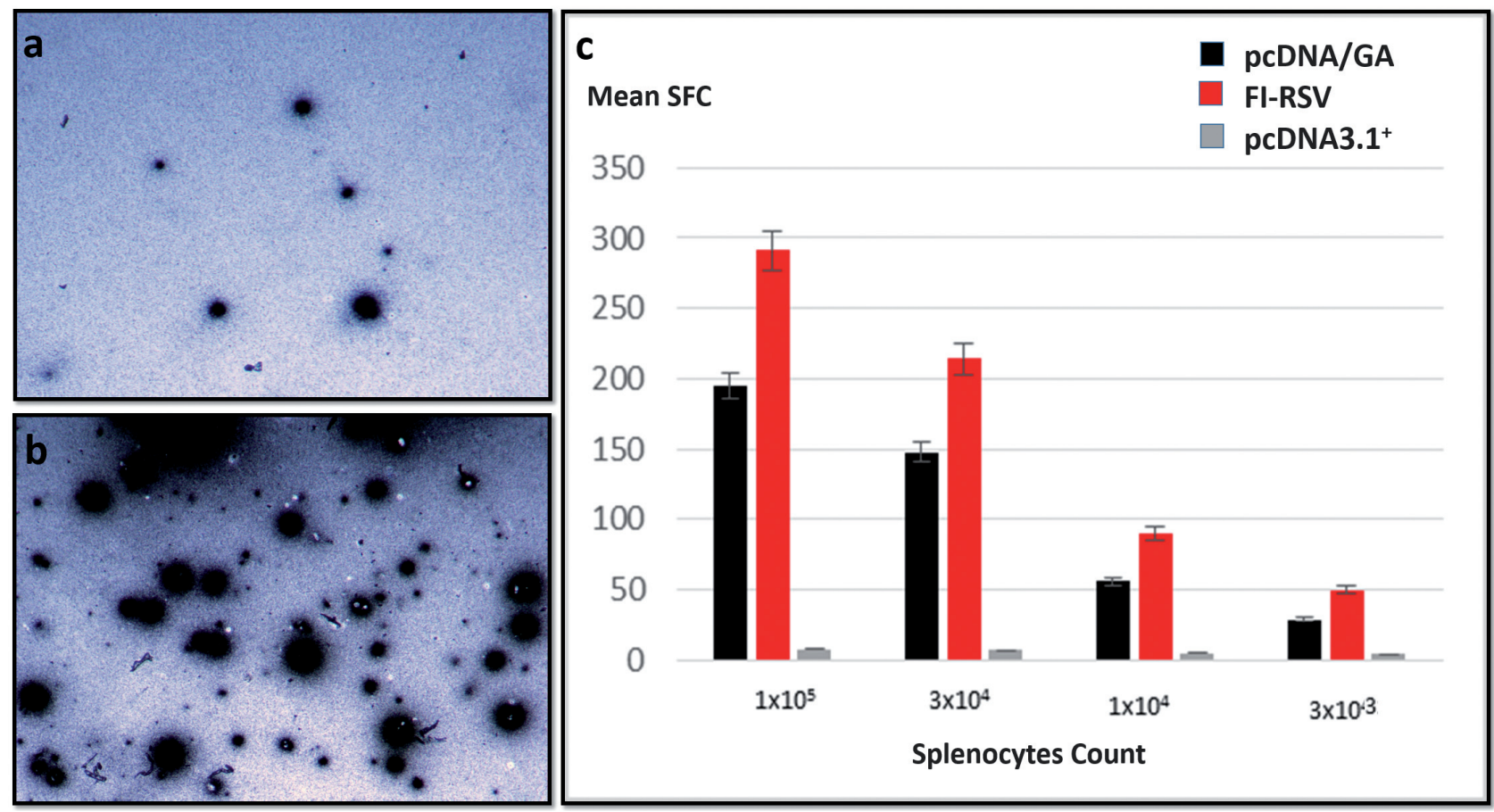

Fig. 3

Ex vivo IFN- $\gamma$ ELISPOT responses following mice immunization with DNA constructs Spots developed in the negative control wells (a) were subtracted from the spots developed in test wells (b). The bars show the mean number of IFN- $\gamma$ secreting cells for pcDNA/GA and pcDNA3.1+ constructs as well as FI-RSV in different concentrations of splenocytes (c).

spots developed in the negative control wells (Fig. 3a) from the mean number of spots developed in the test wells (Fig. 3b) and were expressed as the mean spot forming count of $\mathrm{T}$ cells (SFC). Concanavalin A was used as a positive control for test validation. pcDNA/ GA was able to induce a robust IFN- $\gamma$ production in response to HRSV-A G-derived peptide with a mean SFC range of $187 \pm 6.4$ to $25 \pm 3.5$ at cell densities of $1 \times 10^{5}$ and $3 \times 10^{3}$ cells/well, respectively. FI-RSV showed potent IFN- $\gamma$ induction with a mean SFC that ranged from $283 \pm 20$ to $46 \pm 5.2$ at cell densities of $1 \times 10^{5}$ and $3 \times 10^{3}$ cells/well, respectively, while pcDNA3. $1^{+}$immunized and negative control mice did not show any results that would differ from the negative control (Fig. 3c).

Immunization with $p c D N A / G A$ protects challenged mice from disease progression

The capacity of pcDNA/GA to protect vaccinated subjects was primarily discerned by challenging immunized mice and recording signs of disease progression in terms of mortality rate, weight loss, clinical symptoms, viral load in lungs and pulmonary histopathology. No mortality or significant weight loss was recognized in any of the immunized and control mice groups until the $7^{\text {th }}$ day post-challenge when mice were sacrificed. Similarly, no obvious clinical symptoms were observed.

Lungs of sacrificed mice were extirpated after euthanasia and prepared for virus titration. There was no indication of HRSV replication in lungs of pcDNA/GA immunized and mock-infected mice while the virus titer was calculated as $10^{1.40 \pm 0.10}, 10^{3.70 \pm 0.13}, 10^{3.55 \pm 0.09} \mathrm{TCID}_{50}$ per gram of lung tissue in FI-RSV immunized, pcDNA3.1 $1^{+}$immunized and negative control groups, respectively.

Histopathological examination of formalin-fixed lung tissues collected from FI-RSV immunized mice showed massive peribrochiolar leukocytic aggregation; mainly lymphocytes and plasma cells, with focal necrosis of bronchiolar epithel (Score-3). Mice immunized with pcDNA $3.1^{+}$vector showed perivascular focal aggregation of mononuclear cells and focal damage of alveolar septa (Score-2). Few peri-bronchiolar lymphocytic aggregations with polypoid epithelial cell proliferation in the bronchiolar lumen were observed in lung tissues of pcDNA/GA immunized mice (Score-1). Thickening of the alveolar wall and infiltration by foamy macrophages was also noticed. No signs of inflammation were observed in mock-infected group (Score-0) (Fig. 4). 
(a)

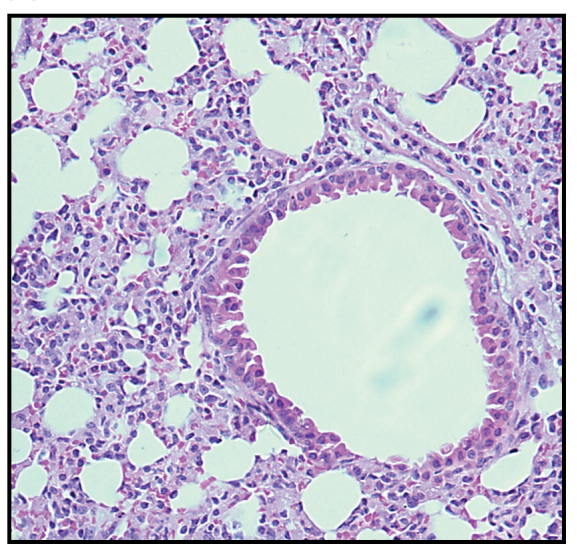

(c)

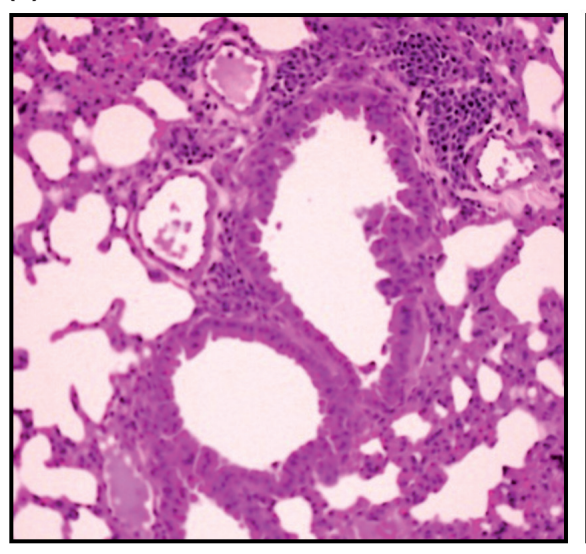

(b)

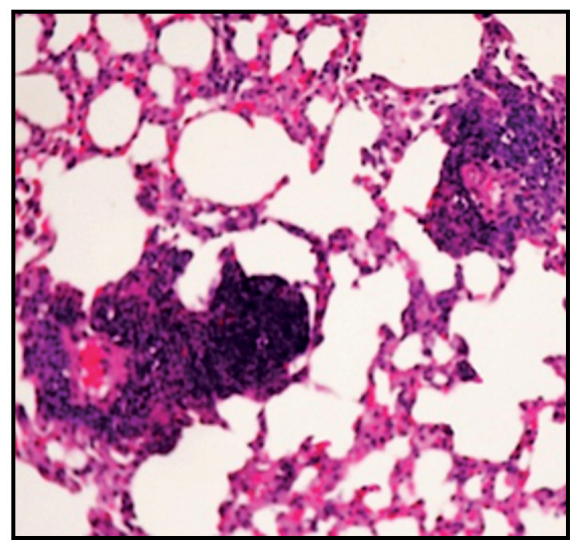

(d)

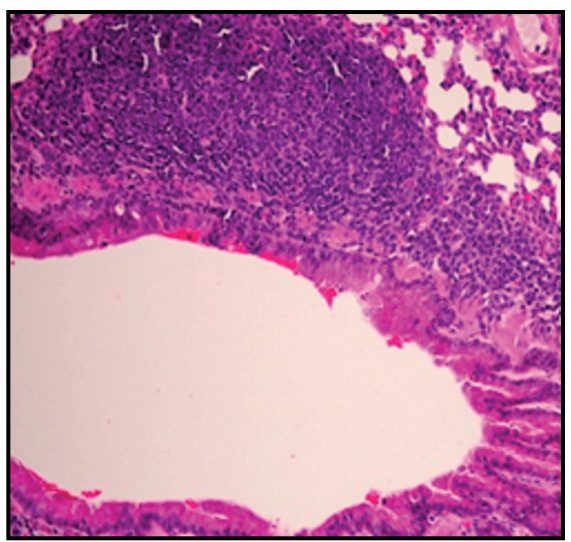

Fig. 4

Pulmonary histopathology of immunized mice post-challenge

(a) Lung section of mock-infected group showing no infiltration of inflammatory cells. (b) Focal aggregation of mononuclear cells and damage of alveolar septa in lung section of pcDNA 3.1 immunized group (c) Few lymphocytic infiltrations in the peri-bronchial spaces with polypoids in the bronchiolar epithel and thickening of the alveolar walls in lung tissue of pcDNA/GA immunized mice. (d) Extensive infiltration of inflammatory cells in the peribronchiolar space and focal necrosis of the epithelial lining in lungs of FI-RSV immunized group. Sections were stained with hematoxylin and eosin. Magnification 200x.

Cytokine analysis predicts effective and safe response in $p c D N A / G A$ immunized mice

The ability of pcDNA/GA to induce safe immune reaction that does not involve Th2 biased response in lungs after challenge was evaluated using RT $^{2}$-PCR Profiler array. The array determines the gene expression profile of 84 mouse-specific antiviral receptors, mediators and signaling components. Fold-regulation changes derived by $\Delta \Delta \mathrm{Ct}$ were calculated in relevance to the positive control group (FI-RSV immunized mice). Genes with at least two-fold change were only considered for analysis. Comparing data of both challenged mice groups showed that pcDNA/GA immunized mice displayed upregulation in interleukin 2 (IL-2), granulocyte macrophage colony stimulating factor (GM-CSF), toll-like receptor 6 (TLR6), B-cell leukemia/lymphoma 6 (BCL6), CCAAT/enhancer binding protein beta (CEBPB), interleukin 4 receptor alpha (IL-4Ra), Janus kinase 3 (JAK3), Jun-B oncogene (JUNB), nuclear factor of activated T-cells 1 (NFATC1), protein tyrosine phosphatase receptor type C (PTPRC), suppressor of cytokine signaling 3 (SOCS3), signal transducer and activator of transcription 6 (STAT6), tumor necrosis factor receptor superfamily member 4 (TNFRSF4) and tumor necrosis factor (ligand) superfamily member 4 (TNFSF4) (Fig. 5a,c). In particular, the characteristic markers for Th1 immune response such as IL2, GM-CSF, and TLR6 were over-expressed by 22-, 3- and 2.4-folds, respectively. Conversely, FI-RSV immunized mice exhibited remarkable upregulation of the inflammatory mediators and cytokines: IL-4, IL-5, IL-6, IL-10, IL-13, interleukin 18 receptor 1 
(a)

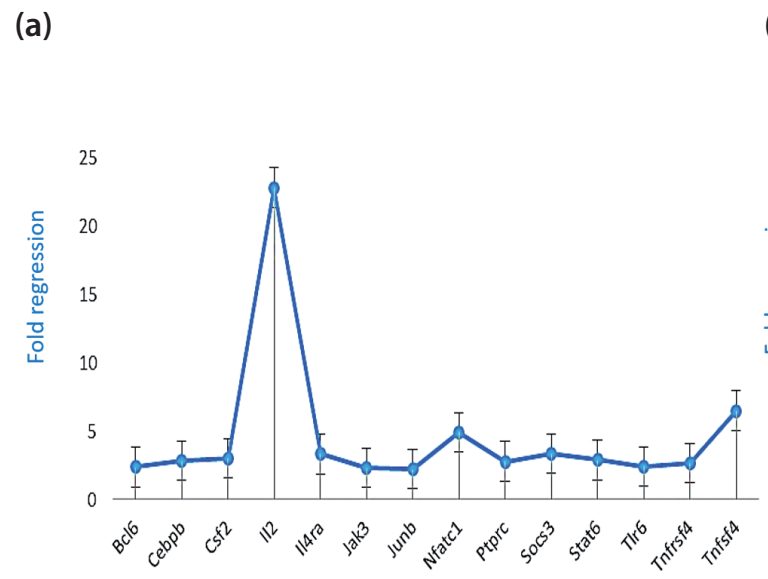

(c)

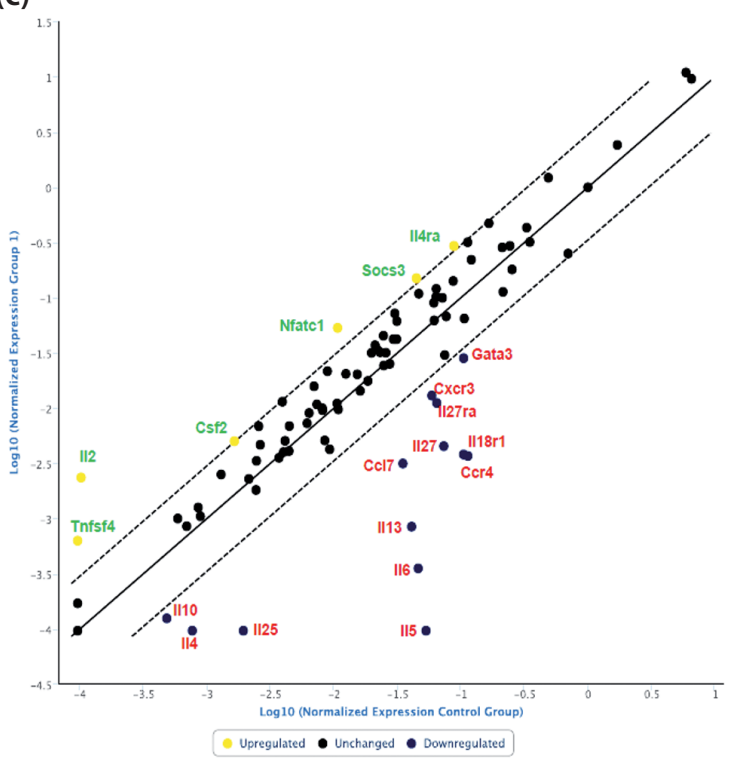

(b)

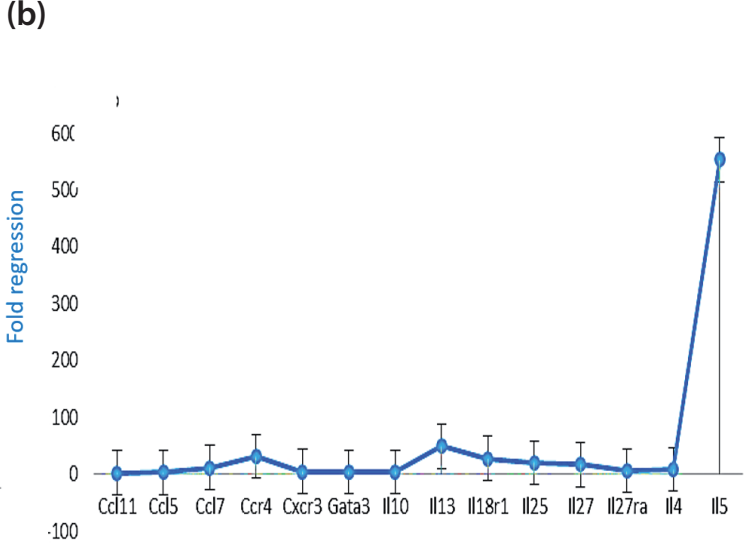

(d)

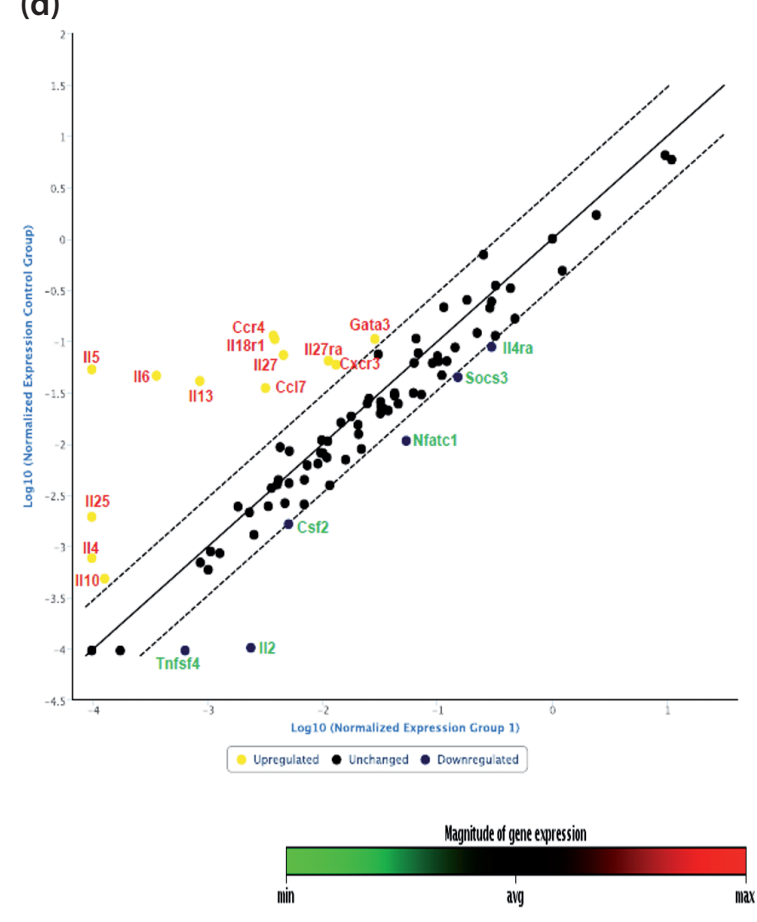

(e)

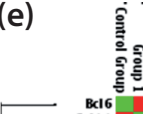

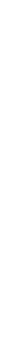

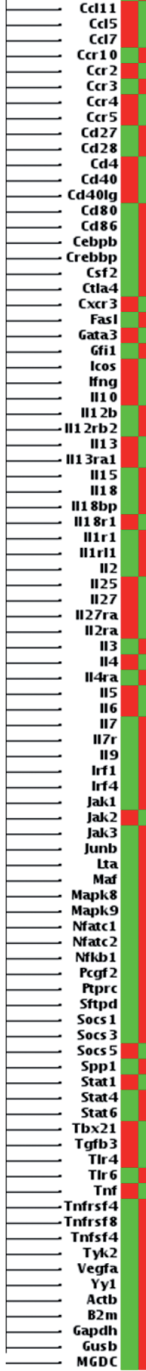

Fig. 5

Evaluation of cytokine gene expression in lungs of challenged mice using RT $^{2}$-PCR Profiler array

Cytokines that revealed two-fold regulation change or more are shown for mice groups immunized either with (a) pcDNA/GA or (b) FI-RSV. The entire array profile was plotted for both mice groups; (c) pcDNA/GA and (d) FI-RSV. The plot enabled clear identification of genes with upregulated, downregulated and unchanged expression. A heat map that shows the relative expression of different array parameters in both mice groups were clustered in non-supervised hierarchical manner with dendrograms indicating co-regulated genes across groups (e).

(IL-18R1), IL-25, IL-27, IL-27Ra, GATA binding protein 3 (GATA3), chemokine C-X-C motif receptor 3 (CXCR3), chemokine $\mathrm{C}-\mathrm{C}$ motif receptor 4 (CCR4), chemokine C-C motif ligand 5 (CCL5), CCL7, CCL11, and SOCS5 (Fig. 5b,d). Th2 biased response was obvious in FI-RSV immunized mice group and was manifested by over-expression of IL-5, IL-6, IL-13, IL-25, IL-27, CCR4 cytokines with a fold increase ranging from 16 (IL-27) to 550 (IL-5).

\section{Discussion}

Protection of infants and young children from the repeated HRSV infections is still a worldwide concern. Failure of the early vaccination trials using FI-RSV in children at the 1960s has hampered the progress toward developing alternative vaccine candidates for decades. As a rule of thumb, based on several animal experiments and clinical trials 
(reviewed by Anderson, (2013), an effective HRSV vaccine should have the following key features: 1) capable to induce protective levels of neutralizing antibodies and $\mathrm{CD}^{+} \mathrm{T}$ cells; 2) stimulate a pattern of $\mathrm{CD} 4^{+} \mathrm{T}$ cell response similar to that of wild-type virus; 3 ) induce a balanced Th1/Th2 immune response; 4 ) would not provoke signs of pulmonary involvement and disease enhancement.

In contrast to FI-RSV, purified peptides and recombinant vaccinia vectors that showed enhancement of pulmonary inflammation and oesinophilia in lungs after virus challenge, live HRSV and naked DNA vaccines induced balanced Th1/ Th2 responses with minimal safety constraints (Andersson et al., 2000; Bembridge et al., 2000; Li et al., 2000; Miller et al., 2002). The genetic stability and prolonged expression of the viral immunogens in DNA vaccines make it a promising approach for the development of an effective HRSV vaccine candidate. Previous studies demonstrated that DNA vectors expressing HRSV G or F proteins can provide protection in mice and cotton rats with limited pathological effect on lung tissue upon HRSV challenge (Bembridge et al., 2000; Li et al., 2000); however the antibody response developed against $\mathrm{F}$ protein may delay up to 12 weeks (Taylor et al., 2005).

Two main claims have been raised for HRSV G protein to decrease its potential as a DNA vaccine candidate. First; it demonstrates high level of heterogeneity among HRSV strains and thus induces subgroup specific immunity. However, recombinant peptides that contain the central conserved domain of $\mathrm{G}$ protein (designated BBG2Na) were able to elicit protective immunity in both HRSV groups in animal studies (Plotnicky-Gilquin et al., 1999; Power et al., 2003). Second; immunization with $G$ protein evokes Th2 biased response and enhanced lung disease. Nevertheless, several studies have explained that the induction of lung pathology is not an intrinsic property of $G$ protein but it mostly depends on the vaccination method, vaccine dose and adjuvant or vehicle used along with the viral immunogen (Bembridge et al., 2000; Li et al., 2000).

In this report, the full-length $G$ gene sequence of HRSV-A Saudi strain was cloned in the mammalian expression vector $\mathrm{pcDNA} 3.1^{+}$. The expression potential of $\mathrm{pcDNA} /$ GA was verified in cell culture using RT-PCR and immunofluorescence assay. pcDNA/GA was capable to induce high levels of neutralizing antibodies and $\mathrm{CD} 8^{+} \mathrm{T}$ cell response in $\mathrm{BALB} / \mathrm{c}$ mice as indicated by ELISA, micro-neutralization and ELISPOT assays. Robust antibody response has proven association with protection of the respiratory pathways from HRSV re-infection, and contribution to viral clearance (Walsh and Falsey, 2004). Earlier vaccination trials using FI-RSV and purified peptides have reported that G protein was weakly immunogenic and induced development of low serum antibody levels with limited neutralization activity (Delgado et al., 2009; Murawski et al., 2010; Waris et al., 1996). The strong antibody response induced by naked DNA vaccines in this study and in others (Bembridge et al., 2000; Li et al., 2000), along with similar results described as a response to recombinant Venezuelan equine encephalitis virus replicon particles and Newcastle disease virus-like particles expressing HRSV G protein (Mok et al., 2007; Murawski et al., 2010), proves that the type and level of antibody response depends on the method of antigen presentation provided by the vaccine and the response of the host immune system toward it.

As outlined earlier, induction of Th1/Th2 balanced immune response and absence of lung immunopathology are two critical identifiers for successful HRSV vaccination. Prior studies have indicated that the over-expression of Th2 associated cytokines (particularly IL-4, IL-5, IL-6, IL-10 and IL-13) in lung tissue augments eosinophil recruitment and development of hypersensitivity response following HRSV challenge (Kim et al., 2003; Waris et al., 1996). To evaluate the safety of pcDNA/GA in mice, the cytokine profile of Th1 and Th2 immune responses was evaluated in lungs post-challenge. It was obvious that Th1 - but not Th 2 - associated cytokines exhibited significant over-expression as compared to FI-RSV immunized control mice. In particular, the key Th1 associated cytokine IL-2 showed 22-fold increased expression in the lungs of pcDNA/GA immunized mice. On the contrary, a substantial increase (16-550-folds) in the level of Th2 associated cytokines (e.g. IL-4, IL-5, IL-6, IL-10, IL-13 and IL-25) was noticeable in lungs of control but not in pcDNA/GA immunized mice. Absence of replicating virus and inflammatory signs in lung tissues of pcDNA/GA immunized mice further confirmed the potential of this construct to prevent disease progression and to avoid lung immunopathology.

Collectively, these results support that immunization with pcDNA/GA does not predispose for enhanced disease in the mouse model. Yet it induces robust humoral and cellular immune responses and provides sufficient protection against live virus challenge in vivo. Additional experiments may be required to recognize the differential response of immunized animals to virus challenge at different time frames and to repeated-exposure to challenge virus. Similar studies are also essential to verify the extent and duration of immunity in other animal models like cotton rats and non-human primates before proceeding to clinical trials in human subjects.

Acknowledgment. This study was supported by the research grant (RGP-VPP), for the Deanship of Scientific Research, King Saud University. The authors would like to thank the members of animal facility unit at College of Pharmacy, King Saud University for their help during animal experiments.

\section{References}

Almajhdi FN, Farrag MA, Amer HM (2014): Genetic diversity in the $G$ protein gene of group A human respiratory syncytial 
viruses circulating in Riyadh, Saudi Arabia. Arch. Virol. 159, 73-81. https://doi.org/10.1007/s00705-013-1792-6 Anderson LJ (2013): Respiratory syncytial virus vaccine development. Semin. Immunol. 25, 160-171. https://doi. org/10.1016/j.smim.2013.04.011

Andersson C, Liljestrom P, Stahl S, Power UF (2000): Protection against respiratory syncytial virus (RSV) elicited in mice by plasmid DNA immunisation encoding a secreted RSV G protein-derived antigen. FEMS Immunol. Med. Microbiol. 29, 247-253. https://doi.org/10.1111/j.1574695X.2000.tb01530.x

Bembridge GP, Garcia-Beato R, Lopez JA, Melero JA, Taylor G (1998): Subcellular site of expression and route of vaccination influence pulmonary eosinophilia following respiratory syncytial virus challenge in $B A L B / c$ mice sensitized to the attachment $G$ protein. J. Immunol. 161, 2473-2480.

Bembridge GP, Rodriguez N, Garcia-Beato R, Nicolson C, Melero JA, Taylor G (2000): DNA encoding the attachment $(G)$ or fusion $(\mathrm{F})$ protein of respiratory syncytial virus induces protection in the absence of pulmonary inflammation. J. Gen. Virol. 81, 2519-2523. https://doi.org/10.1099/00221317-81-10-2519

De Rose R, Taylor EL, Law MG, van der Meide PH, Kent SJ (2005): Granulocyte contamination dramatically inhibits spot formation in AIDS virus-specific ELISpot assays: analysis and strategies to ameliorate. J. Immunol. Methods 297, 177-186. https://doi.org/10.1016/j.jim.2004.12.009

Delgado MF, Coviello S, Monsalvo AC, Melendi GA, Hernandez JZ, Batalle JP, Diaz L, Trento A, Chang HY, Mitzner W, Ravetch J, Melero JA, Irusta PM, Polack FP (2009): Lack of antibody affinity maturation due to poor Tolllike receptor stimulation leads to enhanced respiratory syncytial virus disease. Nat. Med. 15, 34-41. https://doi. org/10.1038/nm.1894

Ghildyal R, Li D, Peroulis I, Shields B, Bardin PG, Teng MN, Collins PL, Meanger J, Mills J (2005): Interaction between the respiratory syncytial virus $\mathrm{G}$ glycoprotein cytoplasmic domain and the matrix protein. J. Gen. Virol. 86, 1879-1884. https://doi.org/10.1099/vir.0.80829-0

Goestch L, Plotnicky-Gilquin H, Champion T, Beck A, Haeuw JF, Nguyen T, Bonnefoy JY, Corvaia N (2000): Influence of live respiratory syncytial virus priming on the immune response generated by a recombinant vaccine candidate, BBG2Na. Vaccine 18, 2648-2655. https://doi.org/10.1016/ $\underline{\text { S0264-410X(00)00064-5 }}$

Graham BS, Perkins MD, Wright PF, Karzon DT (1988): Primary respiratory syncytial virus infection in mice. J. Med. Virol. 26, 153-162. https://doi.org/10.1002/jmv.1890260207

Hwang HS, Lee YT, Kim KH, Park S, Kwon YM, Lee Y, Ko EJ, Jung YJ, Lee JS, Kim YJ, Lee YN, Kim MC, Cho M, Kang SM (2016): Combined virus-like particle and fusion proteinencoding DNA vaccination of cotton rats induces protection against respiratory syncytial virus without causing vaccine-enhanced disease. Virology 494, 215-224 https:// doi.org/10.1016/j.virol.2016.04.014

Jones BG, Sealy RE, Rudraraju R, Traina-Dorge VL, Finneyfrock B, Cook A, Takimoto T, Portner A, Hurwitz JL (2012):
Sendai virus-based RSV vaccine protects African green monkeys from RSV infection. Vaccine 30, 959-968. https://doi.org/10.1016/j.vaccine.2011.11.046

Karron RA, Luongo C, Thumar B, Loehr KM, Englund JA, Collins PL, Buchholz UJ (2015): A gene deletion that up-regulates viral gene expression yields an attenuated RSV vaccine with improved antibody responses in children. Sci. Transl. Med. 7, 312ra175. https://doi.org/10.1126/scitranslmed. aac8463

Kim CK, Kim SW, Park CS, Kim BI, Kang H, Koh YY (2003): Bronchoalveolar lavage cytokine profiles in acute asthma and acute bronchiolitis. J. Allergy Clin. Immunol. 112, 64-71. https://doi.org/10.1067/mai.2003.1618

Kim HW, Canchola JG, Brandt CD, Pyles G, Chanock RM, Jensen K, Parrott RH (1969): Respiratory syncytial virus disease in infants despite prior administration of antigenic inactivated vaccine. Am. J. Epidemiol. 89, 422-434. https:// doi.org/10.1093/oxfordjournals.aje.a120955

Kim KH, Lee YT, Hwang HS, Kwon YM, Jung YJ, Lee Y, Lee JS, Lee YN, Park S, Kang SM (2015): Alum adjuvant enhances protection against respiratory syncytial virus but exacerbates pulmonary inflammation by modulating multiple innate and adaptive immune cells. PLoS One 10, e0139916. https://doi.org/10.1371/journal. pone. 0139916

Li L, Saade F, Petrovsky N (2012): The future of human DNA vaccines. J. Biotechnol. 162,171-182. https://doi. org/10.1016/j.jbiotec.2012.08.012

Li X, Sambhara S, Li CX, Ettorre L, Switzer I, Cates G, James O, Parrington M, Oomen R, Du RP, Klein M (2000): Plasmid DNA encoding the respiratory syncytial virus $G$ protein is a promising vaccine candidate. Virology 269, 54-65. https://doi.org/10.1006/viro.2000.0186

Liu MA, Wahren B, Karlsson Hedestam GB (2006): DNA vaccines: recent developments and future possibilities. Hum. Gene Ther. 17, 1051-1061. https://doi.org/10.1089/ $\underline{\text { hum.2006.17.1051 }}$

Lukens MV, Claassen EA, de Graaff PM, van Dijk ME, Hoogerhout P, Toebes M, Schumacher TN, van der Most RG, Kimpen JL, van Bleek GM (2006): Characterization of the CD8+ $\mathrm{T}$ cell responses directed against respiratory syncytial virus during primary and secondary infection in C57BL/6 mice. Virology 352,157-168. https://doi.org/10.1016/j. virol.2006.04.023

McDermott DS, Knudson CJ, Varga SM (2014): Determining the breadth of the respiratory syncytial virus-specific $\mathrm{T}$ cell response. J. Virol. 88, 3135-3143. https://doi.org/10.1128/ IVI.02139-13

McGinnes LW, Gravel KA, Finberg RW, Kurt-Jones EA, Massare MJ, Smith G, Schmidt MR, Morrison TG (2011): Assembly and immunological properties of Newcastle disease virus-like particles containing the respiratory syncytial virus $\mathrm{F}$ and $\mathrm{G}$ proteins. J. Virol. 85, 366-377. https://doi. org/10.1128/JVI.01861-10

Miller M, Cho JY, Baek KJ, Castaneda D, Nayar J, Rodriguez M, Roman M, Raz E, Broide DH (2002): Plasmid DNA encoding the respiratory syncytial virus $G$ protein protects against RSV-induced airway hyperresponsiveness. 
Vaccine 20, 3023-3033. https://doi.org/10.1016/S0264410X(02)00217-7

Mok H, Lee S, Utley TJ, Shepherd BE, Polosukhin VV, Collier ML, Davis NL, Johnston RE, Crowe JE (2007): Venezuelan equine encephalitis virus replicon particles encoding respiratory syncytial virus surface glycoproteins induce protective mucosal responses in mice and cotton rats. J. Virol. 81, 13710-13722. https://doi.org/10.1128/ JVI.01351-07

Murawski MR, McGinnes LW, Finberg RW, Kurt-Jones EA, Massare MJ, Smith G, Heaton PM, Fraire AE, Morrison TG (2010): Newcastle disease virus-like particles containing respiratory syncytial virus $G$ protein induced protection in BALB/c mice, with no evidence of immunopathology. J. Virol. 84, 1110-1123. https://doi.org/10.1128/ JVI.01709-09

Murphy BR, Prince GA, Collins PL, Hildreth SW, Paradiso PR (1991): Effect of passive antibody on the immune response of cotton rats to purified $\mathrm{F}$ and $\mathrm{G}$ glycoproteins of respiratory syncytial virus (RSV). Vaccine 9, 185-189. https:// doi.org/10.1016/0264-410X(91)90151-U

Nair H, Nokes DJ, Gessner BD, Dherani M, Madhi SA, Singleton RJ, O'Brien KL, Roca A, Wright PF, Bruce N, Chandran A, Theodoratou E, Sutanto A, Sedyaningsih ER, Ngama M, Munywoki PK, Kartasasmita C, Simoes EA, Rudan I, Weber MW, Campbell H (2010): Global burden of acute lower respiratory infections due to respiratory syncytial virus in young children: a systematic review and metaanalysis. Lancet 375, 1545-1555. https://doi.org/10.1016/ S0140-6736(10)60206-1

Plotnicky-Gilquin H, Huss T, Aubry JP, Haeuw JF, Beck A, Bonnefoy JY, Nguyen TN, Power UF (1999): Absence of lung immunopathology following respiratory syncytial virus (RSV) challenge in mice immunized with a recombinant RSV G protein fragment. Virology 258, 128-140. https:// doi.org/10.1006/viro.1999.9702

Polack FP (2015): The changing landscape of respiratory syncytial virus. Vaccine 33, 6473-6478. https://doi.org/10.1016/j. vaccine.2015.06.119

Power UF, Plotnicky-Gilquin H, Huss T, Robert A, Trudel M, Stahl S, Uhlen M, Nguyen TN, Binz H (1997): Induction of protective immunity in rodents by vaccination with a prokaryotically expressed recombinant fusion protein containing a respiratory syncytial virus $G$ protein fragment. Virology 230,155-166. https://doi.org/10.1006/viro.1997.8465

Power UF, Plotnicky H, Blaecke A, Nguyen TN (2003): The immunogenicity, protective efficacy and safety of BBG2Na, a subunit respiratory syncytial virus (RSV) vaccine candidate, against RSV-B. Vaccine 22, 168-176. https://doi. org/10.1016/S0264-410X(03)00570-X

Quan FS, Kim Y, Lee S, Yi H, Kang SM, Bozja J, Moore ML, Compans RW (2011): Virus-like particle vaccine induces protection against respiratory syncytial virus infection in mice. J. Infect. Dis. 204, 987-995. https://doi.org/10.1093/infdis/jir474

Sparer TE, Matthews S, Hussell T, Rae AJ, Garcia-Barreno B, Melero JA, Openshaw PJ (1998): Eliminating a region of respiratory syncytial virus attachment protein allows induction of protective immunity without vaccine-enhanced lung eosinophilia. J. Exp. Med. 187, 1921-1926. https://doi. org/10.1084/jem.187.11.1921

Stab V, Nitsche S, Niezold T, Storcksdieck Genannt Bonsmann M, Wiechers A, Tippler B, Hannaman D, Ehrhardt C, Uberla K, Grunwald T, Tenbusch M (2013): Protective efficacy and immunogenicity of a combinatory DNA vaccine against influenza $\mathrm{A}$ virus and the respiratory syncytial virus. PLoS One 8, e72217. https://doi.org/10.1371/ journal.pone.0072217

Subbarayan P, Qin H, Pillai S, Lee JJ, Pfendt AP, Willing G, Miller ME, Dennis VA, Singh SR (2010): Expression and characterization of a multivalent human respiratory syncytial virus protein. Mol. Biol. (Mosk) 44, 477-487. https://doi. org/10.1134/S0026893310030106

Taylor G, Bruce C, Barbet AF, Wyld SG, Thomas LH (2005): DNA vaccination against respiratory syncytial virus in young calves. Vaccine 23, 1242-1250. https://doi.org/10.1016/j. vaccine.2004.09.005

Tregoning JS, Schwarze J (2010): Respiratory viral infections in infants: causes, clinical symptoms, virology, and immunology. Clin. Microbiol. Rev. 23, 74-98. https://doi. org/10.1128/CMR.00032-09

Varga SM, Wissinger EL, Braciale TJ (2000): The attachment (G) glycoprotein of respiratory syncytial virus contains a single immunodominant epitope that elicits both Th1 and Th2 CD4+ T cell responses. J. Immunol. 165, 6487-6495. https://doi.org/10.4049/jimmunol.165.11.6487

Vaughan K, Rhodes GH, Gershwin LJ (2005): DNA immunization against respiratory syncytial virus (RSV) in infant rhesus monkeys. Vaccine 23, 2928-2942. https://doi. org/10.1016/j.vaccine.2004.10.046

Walsh EE, Falsey AR (2004): Humoral and mucosal immunity in protection from natural respiratory syncytial virus infection in adults. J. Infect. Dis. 190, 373-378. https:// doi.org/10.1086/421524

Waris ME, Tsou C, Erdman DD, Zaki SR, Anderson LJ (1996): Respiratory synctial virus infection in $\mathrm{BALB} / \mathrm{c}$ mice previously immunized with formalin-inactivated virus induces enhanced pulmonary inflammatory response with a predominant Th2-like cytokine pattern. J. Virol. 70, 2852-2860.

WHO (2005): Initiative for vaccine research: respiratory syncytial virus (RSV).

Wright PF, Karron RA, Belshe RB, Thompson J, Crowe JE, Jr., Boyce TG, Halburnt LL, Reed GW, Whitehead SS, Anderson EL, Wittek AE, Casey R, Eichelberger M, Thumar B, Randolph VB, Udem SA, Chanock RM, Murphy BR (2000): Evaluation of a live, cold-passaged, temperaturesensitive, respiratory syncytial virus vaccine candidate in infancy. J. Infect. Dis. 182, 1331-1342. https://doi. org/10.1086/315859

Wu H, Dennis VA, Pillai SR, Singh SR (2009): RSV fusion (F) protein DNA vaccine provides partial protection against viral infection. Virus Res. 145, 39-47. https://doi.org/10.1016/j. virusres.2009.06.012

Xu Y, Yuen PW, Lam JK (2014): Intranasal DNA Vaccine for Protection against Respiratory Infectious Diseases: The Delivery Perspectives. Pharmaceutics 6, 378-415. https:// doi.org/10.3390/pharmaceutics6030378 